\title{
Inflammation-Mediated Hyperexcitability of Sensory Neurons
}

\author{
Michael S. Gold ${ }^{a-c}$ Natasha M. Flake ${ }^{a}$ \\ ${ }^{a}$ Department of Biomedical Sciences, Dental School, ${ }^{b}$ Program in Neuroscience, and \\ ${ }^{\mathrm{c}}$ Department of Anatomy and Neurobiology, Medical School, University of Maryland, Baltimore, Md., USA
}

\section{Key Words}

Second messenger pathway $\cdot$ Neuroplasticity ·

Target of innervation

\begin{abstract}
One of the most prominent signs of tissue injury and inflammation is pain and pain continues to be the primary reason people seek medical attention. Inflammatory pain reflects, at least in part, an increase in the excitability, or sensitization, of subpopulations of primary afferent neurons. While the sensitization of high threshold afferents was observed almost 40 years ago, the basis for this phenomenon continues to be an active and fertile area of research today. This review will summarize recent advances in our mechanistic understanding of sensitization, focusing on four general areas where research has been most active or productive. These include: (1) the characterization of second messenger pathways underlying inflammation-induced changes in afferent excitability; (2) the impact of previous injury on the afferent response to subsequent inflammation; (3) the impact of target of innervation on the specific afferent response to inflammation, and (4) the impact of sex hormones on the sensitization of high threshold afferents. Work in these areas highlights how much has been learned about this process as well as how much there is yet to learn.
\end{abstract}

\section{Introduction}

Tissue injury results in a sequence of physiological processes that are responsible for limiting the extent of tissue damage as well as repairing the damaged tissue. These processes involve a series of feedback and feed forward interactions among the immune system, the peripheral nervous system (PNS), and the central nervous system (CNS). The result is a change in tissue structure and function that is generically referred to as inflammation and is characterized by five cardinal signs: redness, swelling, heat, loss of function and pain. While huge strides have been made in our understanding of the specific processes underlying each of these five cardinal signs, the focus of the following discussion is pain. The following discussion is focused further on inflammatory processes influencing the excitability of primary afferent (i.e. sensory) neurons, acknowledging both that pain is necessarily a phenomenon involving activation of supra-spinal structures within the CNS and that there is a wealth of new data on CNS mechanisms involved in the expression of inflammatory pain. Finally, because there are several comprehensive reviews addressing the role of the primary afferent in inflammatory hyperalgesia [1-3], we have addressed areas where significant advances have recently been made.

There are several reasons we have chosen to focus on the primary afferent neuron. First, activity in nociceptive afferents, a subpopulation of sensory neurons responsive

\section{KARGER \\ Fax +4161306 1234 E-Mail karger@karger.ch} www.karger.com 
to tissue damaging stimuli, is a necessary first step in the sensation of pain following noxious stimulation of peripheral tissue. Second, activity in this population of neurons is critical for the full expression of the inflammatory response [4]. And third, nociceptor sensitization is involved in one of the more striking aspects of inflammatory pain: the increased sensitivity to normally noxious stimuli [2].

Nociceptor sensitization is a generic term used to describe any increase in the transmission of nociceptive information. At a mechanistic level, an increase in the transmission of nociceptive information may reflect changes in any one of four general processes necessary for afferent signaling. The first involves stimulus transduction. This is the conversion of energy from the environment (thermal, mechanical or chemical) into a change in membrane potential, generally referred to as a generator potential. The second process involves action potential initiation. At this step, the generator potential resulting from stimulus transduction is converted into an action potential. The third process involves action potential propagation, in which action potentials are rapidly conducted along the axon. And the final process is transmitter release. At this step, action potentials invading the central (or peripheral) terminals of afferents drive an influx of calcium sufficient to enable vesicular release of transmitter. Inflammatory mediators may influence each of these processes, thereby increasing the transmission of nociceptive information in several ways within the same neuron [5-8].

Research to date has primarily focused on the role of various ion channels in each of these processes [1,9]. For example, there is extensive literature on the modulation of the capsaicin/heat receptor, TRPV1 (formerly VR1), a transducer that is critical for the expression of inflammatory hyperalgesia [7]. As discussed below, inflammatory mediators influence the gating of TRPV1 such that the channel activates at lower temperatures and is more resistant to desensitization. There is also a rich literature on the modulation of voltage-gated sodium channels, in particular the tetrodotoxin-resistant channel NaV1.8 [5]. This channel is involved in spike initiation $[10,11]$ and also appears to be critical for the expression of inflammatory hyperalgesia $[12,13]$. As with TRPV1, inflammatory mediators influence the gating [14] and expression [15] of NaV1.8. Similarly, there is circumstantial evidence that modulation of the hyperpolarization activated cationic current, $\mathrm{I}_{\mathrm{h}}$ underlies an increase in axon conduction velocity observed in the presence of inflammation $[16,6]$. Finally, while there is extensive data detailing the inflammatory mediator-induced increase in transmitter release from nociceptive afferents [8], it was only recently demonstrated in mammalian neurons that this increased release may reflect modulation of voltage-gated calcium channels [17]. Much of this work, as well as a number of other important studies, has been reviewed previously [9].

Major advances in our understanding of the processes underlying inflammation-induced sensitization of nociceptive afferents have come in four general areas. The first is the second messenger pathways underlying the actions of inflammatory mediators. The second is the impact of previous injury on the subsequent sensitization of nociceptive afferents. The third is the impact of target of innervation on the sensitization of nociceptive afferents. And the fourth is the impact of gonadal hormones on the sensitization of nociceptive afferents. The following discussion constitutes a brief review of the advances made in these four general areas.

\section{Second Messenger Pathways}

Implied in the discussion of peripheral sensitization up until this point is the distinction between activation and sensitization. Activation is a process involving membrane depolarization of sufficient magnitude to induce action potential generation in the primary afferent. Such a process may reflect ligand binding to an ionotropic receptor such as the acid sensing ion channel 3 (ASIC3), or TRPV1. In contrast, sensitization refers to the modulation (i.e. phosphorylation/dephosphorylation, cellular trafficking, etc.) of cellular proteins and/or expression levels resulting in changes in ion channel activity and/or density with a subsequent increase in the excitability of the neuron. By definition, therefore, sensitization involves the activation of second messenger pathways.

Primary afferent neurons express a number of receptors for various inflammatory mediators. Space does not permit an exhaustive list of receptors present in sensory neurons, but suffice it to say that multiple isoforms of receptors for virtually every class of inflammatory mediator are expressed in sensory neurons $[1,2]$. Many of these receptors are G-protein-coupled receptors. Not surprisingly, the most extensively studied second messenger pathways in sensory neurons are those underlying the activation of protein kinase $\mathrm{A}$ (PKA) and protein kinase $\mathrm{C}$ (PKC) $[1,2]$. Indeed, both pathways have been shown to contribute to inflammatory hyperalgesia $[18,19]$, nociceptor sensitization [20-25] and the modulation of spe- 
cific ion channels involved in the regulation of nociceptor excitability [26-34].

While there have been several studies designed to elucidate mechanisms underlying the cellular targeting of activated PKA [35] as well as the specific protein residues responsible for PKA-induced modulation of channel activity [14], recent work on these classical second messenger systems has focused on the PKC pathway. Much of this work has been directed at the identification of the PKC isoforms underlying nociceptor sensitization. Eleven PKC isoforms have been identified to date and anywhere from 5 [31] to 10 [36] of these are present in sensory neurons. The most compelling evidence supports a role for PKCe, a 'novel' (i.e. diacyl glycerol (DAG)-dependent, $\mathrm{Ca}^{2+}$-independent) PKC isoform, in nociceptor sensitization. The inflammatory mediators bradykinin and epinephrine activate PKC $\varepsilon$ [31, 36], presumably secondary to the activation of phospholipase $\mathrm{C}$ (PLC) and the liberation of diacylglycerol (DAG). Bradykinin has been shown to induce translocation of PKC 8 [31], but not other isoforms present in sensory neurons, to the plasma membrane. $\mathrm{PKC} \varepsilon$ is phosphorylated in sensory neurons in the presence of persistent inflammation [37]. Inflammatory hyperalgesia and nociceptor sensitization are significantly attenuated by a specific inhibitor of PKC $\varepsilon$ as well as in $\mathrm{PKC} \varepsilon$ null mutant mice [36]. Interestingly, $\mathrm{PKC} \varepsilon$-dependent hyperalgesia is dependent on an intact cytoskeleton [38]. This cytoskeleton requirement contrasts with PKA-mediated hyperalgesia. Finally, two cellular targets have been identified to date that appear to underlie $\mathrm{PKC} \varepsilon$-mediated nociceptor sensitization: TRPV1 [31] and NaV1.8 [36]. In short, PKC $\varepsilon$ appears to contribute to both the initiation and maintenance of inflammatory hyperalgesia via modulation of several ion channels involved in the control of nociceptor excitability.

Other PKC isoforms that have been implicated in nociceptor sensitization include a 'classical' PKC isoform, $\mathrm{PKC} \alpha$, and at least one 'classical' isoform that remains to be identified. PKC $\alpha$ has been implicated in the activation of TRPV1 [39]. This isozyme was implicated by a correlation between the selective down-regulation of PKC $\alpha$ observed following chronic phorbol ester treatment and the concomitant loss of acute phorbol ester-induced activation of TRPV1. The 'classical' PKC isoform that has yet to be identified was also implicated in a study involving the use of phorbol esters to activate PKC, in this case, to study the inhibition of a potassium channel in cultured sensory neurons [32]. Inhibition of this channel appears to contribute to inflammatory mediator-induced noci- ceptor sensitization [28]. The phorbol ester (PDBu)-induced inhibition of this current depended on the holding potential (i.e. it was only observed when neurons were held at relatively depolarized membrane potentials) and could be blocked with selective blockers of voltage-gated calcium channels as well as nonspecific PKC antagonists. Thus, because both a DAG analog and an increase in intracellular $\mathrm{Ca}^{2+}$ are necessary for PKC-induced inhibition of this $\mathrm{K}^{+}$current, a 'classical' PKC isoform appears to be responsible.

The nitric oxide (NO)/guanyle cyclase (GC)/cGMP pathway has also received significant attention lately. That this pathway is involved in the modulation of afferent activity and therefore nociception has been appreciated for some time now, as evidence from behavioral studies suggested that the peripheral antinociceptive actions of opioids involved the NO/cGMP pathway [40]. More recently, it was reported that this pathway underlies pain induced by bradykinin $[41,42]$ and contributes to the development of prostaglandin E2 $\left(\mathrm{PGE}_{2}\right)$-induced hyperalgesia [43]. Unfortunately, there has been as much conflict in single unit studies as in behavioral studies as it has been reported that the NO/cGMP pathway (1) has no effect on cutaneous afferent activity [21]; (2) decreases articular afferent activity [44], and (3) increases cutaneous afferent activity [45]. These apparently discrepant observations may reflect a differential role for this pathway in the initiation versus maintenance of sensitization. That is, activation of this pathway appears to underlie the initiation of nociceptor sensitization via an increase in NaV1.8 [43]. However, after sensitization has fully developed, and is apparently maintained by other cellular processes, activation of this pathway appears to underlie antinociception via activation of a potassium channel [46]. Unfortunately, this hypothesis does not account for the observation that the NO/cGMP pathway leads to the inhibition of articular afferents in both naïve and arthritic rats [44]. An alternative hypothesis is that there are different subpopulations of afferents that are either sensitized, inhibited or unaffected by NO/cGMP [47]. The relative importance of these different populations of afferents to pain behavior may vary during initiation and maintenance of inflammation as well as by target of innervation. Consistent with this suggestion, there is evidence that activation of the NO/cGMP pathway is pronociceptive or antinociceptive according to site of injection: intradermal activation of this pathway is pronociceptive and subcutaneous activation of this pathway is antinociceptive [47]. Similarly, it has recently been reported that there are subpopulations of dural afferents 
that could be distinguished according to whether they were sensitized, inhibited or unaffected by NO [48]. Interestingly, the most excitable neurons were the most likely to be inhibited. It is also interesting to note that while NO produced variable effects on dural afferents, cGMP was always inhibitory, suggesting that subpopulations of nociceptive afferents are not only distinguished by whether a second messenger pathway is excitatory or inhibitory, but at which point along a pathway a mediator becomes excitatory or inhibitory.

In addition to these new twists on 'old' second messenger pathways, four relatively novel signaling pathways have recently been implicated. The first of these involve lipid mediators that have been implicated in the regulation of TRPV1 activity as well as that of other ion channels (NaV1.8 and a potassium channel). Interestingly, the inflammatory mediator, nerve growth factor (NGF), may initiate the regulation of all three ion channels. TRPV1 regulation is clearly a complex process involving several different stimuli including protons, temperature and endogenous lipid agonists such as anandemide. The channel also appears to be constitutively inhibited by plasma membrane phosphatidylinositol-4,5-bisphosphate (PtdIns(4,5)P2) [49]. As a result, TRPV1 sensitization by inflammatory mediators such as NGF and bradykinin actually involve disinhibition. That is, these inflammatory mediators drive the activation of PLC which hydrolysizes PtIns(4,5)P2 to DAG and inositol trisphosphate (IP3), thereby removing the inhibition of TRPV1. The NGF effect is mediated through TrkA receptors coupled to PLC $\gamma$ and all three molecules, TRPV1, TrkA and PLC $\gamma$, exist in a ternary complex [49]. This disinhibition mechanism was demonstrated in heterologous expression systems and in cell-free patches from sensory neurons. The involvement of this PLC $\gamma$-dependent pathway was replicated in a subsequent study in sensory neurons in which calcium imaging was used to assess NGF-induced sensitization of capsaicin-evoked responses [50]. In this study, PLC inhibition with neomycin resulted in the inhibition of the NGF-induced sensitization.

NGF appears to utilize yet another second messenger pathway in the modulation of sodium and potassium channels. This second lipid mediator-dependent pathway appears to involve the low-affinity neurotrophin receptor p75 [51]. NGF binding to $p 75$ has been shown to result in the activation of sphingomyelinase and the subsequent liberation of ceramide from membrane sphingomyelin [52]. In support of such a pathway, NGF-induced sensitization of isolated sensory neurons was inhibited by an inhibitor of sphingomyelinase, and replicated by the ap- plication of sphingomyelinase or cerimide. This NGFinduced increase in excitability was associated with the potentiation of NaV1.8 and the suppression of a potassium current. While data from a p75 knock-out mouse sheds a cautionary light over these observations, in that NGF-induced hyperalgesia was fully manifest in these mice [53], the deletion construct left open the possibility that functional $\mathrm{p} 75$ protein is still present in these mice [54]. Thus, acute NGF-induced sensitization appears to reflect the modulation of several different ion channels subsequent to the activation of several second messenger pathways.

Another relatively novel second messenger pathway implicated in the sensitization of nociceptive afferents involves the activation of two mitogen-activated protein kinase(MAPK) family members: ERK $1 / 2$ and $\mathrm{p} 38 \mathrm{MAPK}$ (p38). Activation of these two kinases involves distinct second messenger pathways. Activation of ERK1/2 reflects activation of the small G-protein-binding molecule, Ras, and the subsequent activation of MEK1/2. Activation of $\mathrm{p} 38$ reflects the activation of a number of upstream molecules including MEKK and MKK3/6. Both ERK1/2 and $\mathrm{p} 38$ are activated in a number of cell types by stress, and therefore it is not surprising that both are activated in sensory neurons following tissue injury. Interestingly, the type of injury influences the pattern of activation. For example, nerve injury results in ERK1/2 activation in medium- and large-diameter sensory neurons [55] and either a decrease in the number of neurons in which activated p38 is detectable [56] or a delayed activation of p38 in both large and small diameter sensory neurons [57]. In contrast, both ERK $1 / 2$ and p38 are activated in small-diameter, TrkA-expressing neurons in the presence of inflammation [58, 55].

Activation of ERK1/2 and/or p38 may contribute to inflammation-induced sensitization of sensory neurons in several distinct ways. First, ERK1/2 appears to contribute, at least in part, to a rapid, presumably phosphorylation-dependent, G-protein-mediated sensitization of nociceptive afferents. This pathway is suggested by the observation that inhibition of ERK1/2 activation with the peripheral administration of MEK1/2 antagonist significantly attenuated epinephrine-induced hyperalgesia [59]. While the downstream targets of ERK $1 / 2$ activation in the terminals of nociceptive afferents have yet to be identified, ERKs have been shown to inhibit A-type potassium currents in superficial dorsal horn neurons [60]. Second, noxious stimulation of peripheral tissue results in a rapid activation of ERK $1 / 2$ in the afferent cell body. Afferent activity appears to be sufficient for this mode of 
ERK1/2 activation, as phosphorylated ERK1/2 is detectable in sensory neuron cell bodies within 2 min of nociceptor activation $[61,62]$. Based on previous data from PC12 cells [63], it would appear that an activity-induced increase in intracellular $\mathrm{Ca}^{2+}$ is sufficient to induce this ERK1/2 activation. Given that much of this rapidly activated ERK1/2 is translocated to the nucleus, this ERK1/2 activation may mediate transcriptional changes in response to tissue injury and therefore a more persistent change in afferent excitability. And third, NGF, via TrkA receptor activation, appears to mediate the activation of both ERK1/2 and p38 [64]. This activation occurs in peripheral tissue and appears to serve as a retrograde signal to the sensory neuron cell body, as NGF and activated TrkA, ERK1/2 and p38 are found in early endosomes in peripheral nerves. Consistent with the suggestion that this pathway in important for the expression of inflammatory hyperalgesia, it has been demonstrated that this NGF-dependent activation of p38 underlies an increase in TRPV1 protein transported to the periphery and heat hyperalgesia following CFA injection [58]. Interestingly, the increase in TRPV1 protein was not associated with an increase in TRPV 1 mRNA, raising the possibility that p38 activation influences the post-transcriptional processing of TRPV1. In contrast, the inflammation-induced increase in ERK1/2 activation results in an increase in the expression of brain derived neurotrophic factor (BDNF) [55], another molecule that appears to contribute to the expression of inflammatory hyperalgesia. Thus, activation of ERK1/2 and p38 appear to contribute to both the initiation and maintenance of inflammatory hyperalgesia by influencing cellular processes at several sites within the sensory neuron.

Finally, there is recent evidence suggesting that two additional kinases contribute to nociceptor sensitization and/or inflammatory hyperalgesia. These include the $\mathrm{Ca}^{2+}$-calmodulin-dependent protein kinase II (CaMKII) and phosphatidylinositol-3 kinase (PI3K). There is considerably more evidence of a spinal role for CaMKII in nociception. However, inhibition of CaMKII has been shown to inhibit NGF-induced sensitization of capsaicinevoked responses in sensory neurons [50]. Furthermore, persistent inflammation is associated with an increase in the expression of the $\alpha$-subunit of CaMKII [65]. PI3K is activated by a number of cytokines and is generally thought to be involved in the regulation of the transcriptional factor NF- $\mathrm{KB}$. However, evidence that this enzyme contributes to the acute sensitization of nociceptive afferents comes from the observation that inhibition of PI3K was even more effective at inhibiting NGF-induced sensitization of capsaicin-evoked responses than was inhibition of PLC $\gamma$ [50]. While these PI3K results were somewhat surprising, an NGF-induced activation of PI3K in sensory neurons has been implicated in another study [64].

\section{The Impact of Previous Noxious Stimuli}

Investigators have been describing inflammation-induced changes in gene expression in sensory neurons since the methods have been available to perform such experiments. What has been striking about these studies is that marked changes in gene expression have been observed in response to insults that produce relatively short lasting inflammation. For example, an increase in NaV1.8 mRNA is observed in DRG neurons 3 days after induction of inflammation with carageenan [15]. And even though a relatively large dose of carageenan was used in this study, carageenan-induced inflammation generally resolves within 1-3 days. The implication of these observations is that persistent changes in gene expression may provide the substrate for a 'memory' of the original insult that should impact the response to subsequent injury.

Research into this area has led to two striking observations. One of these observations is that there are indeed mechanisms by which the 'memory' of past insults is retained in primary afferents [66-68]. Indeed, recent evidence suggests that an initial inflammatory insult results in an increase in the expression of the N-type calcium channel CaV2.2 which contributes to an increase in the response to a subsequent inflammatory challenge [69]. However, such a change in protein expression is only one component of the 'memory'. That is, the memory also appears to reflect a change in the second messenger pathways underlying nociceptor sensitization. This issue has been demonstrated most clearly with $\mathrm{PGE}_{2}$. In naïve tissue, $\mathrm{PGE}_{2}$-induced hyperalgesia and nociceptor sensitization reflects activation of the CAMP/PKA second messenger system and lasts from 1 to $3 \mathrm{~h}$ following a single intradermal injection [18]. However, up to 21 days (the longest time point tested) following resolution of a brief inflammatory insult, $\mathrm{PGE}_{2}$-induced hyperalgesia reflects activation of a $\mathrm{PKC} \varepsilon$-dependent pathway and lasts for more than $24 \mathrm{~h} \mathrm{[67].} \mathrm{PKC \varepsilon} \mathrm{appears} \mathrm{to} \mathrm{be} \mathrm{necessary} \mathrm{for}$ both the initiation of this inflammatory memory, as well as the expression of the re-inflammation-induced hyperalgesia [70].

The second observation regarding the long-term consequences of inflammation is that there appears to be a 
critical period in development within which noxious stimuli and/or stress permanently alters developing nociceptive circuitry [71-76]. The phenotype in the adult appears to depend on a number of factors including the duration and intensity of the early noxious stimulus as well as the tissue inflamed. For example, injecting rats with a small dose of CFA in the fist week of life, but not after the second week of life, results in an adult rat with a normal baseline nociceptive threshold, but enhanced hyperalgesia following re-inflammation [72]. In contrast, a brief $(<24 \mathrm{~h})$ inflammatory stimulus in rat pups between $\mathrm{P} 0$ and $\mathrm{P} 8$ results in an adult rat that demonstrates a baseline hypoalgesia and hyper-responsiveness to re-inflammation [76]. Data from both human and animals studies on the effects of neonatal injury and stress has recently been reviewed elsewhere [77].

Similar to the variability in the adult phenotype observed following neonatal injury and stress, the relative contribution of the primary afferent also appears to vary according to the nature and location of the injury. For example, neonatal colonic inflammation is associated with a baseline hypersensitivity in the adult that reflects, at least in part, hypersensitive colonic afferents [75]. In contrast, the hypoalgesia observed following a brief inflammation of the hindpaw appears to reflect a more global change in nociceptive processing [76]. And the re-inflammation hypersensitivity observed in the neonatal CFA model is associated with an increase in the density, as well as caudal spread of afferent terminals in the spinal cord [72]. Finally, data from a recent study suggests that neonatal inflammation-induced changes in adult behavior or primary afferent properties are only observed if there were persistent signs of inflammation [78]. Thus, there is clearly much work to be done in this area both in terms of our understanding of the impact of various stimuli on developing nociceptive circuitry as well as the relevance of data gleaned from animal models to human experiences.

\section{Target of Innervation}

As the pain research community has shifted its focus from the processing of acute pain to that of persistent pain, researchers have begun to explore the impact of inflammation in different tissues at a more mechanistic level [79-85]. Motivation for these studies reflects the fact that pain associated with specific body regions may be both qualitatively and quantitatively distinct. One of the most striking observations to arise from this line of re- search is that the response to inflammation of different populations of nociceptive afferents, defined by their target of innervation, is distinct. For example, persistent inflammation of cutaneous tissue in the rat is associated with sensitization of cutaneous afferents which is characterized by an increase in the slope of the stimulus response function with little if any change in mechanical threshold [86]. Inflammation of the rat knee joint is associated with the sensitization of articular afferents that is characterized by a decrease in mechanical threshold and an increase in the slope of the stimulus response function [87]. And the sensitization of low threshold colonic afferents appears to primarily reflect a leftward shift in the mechanical stimulus response function with little change in the slope [88]. Of course it is always possible that these different modes of sensitization reflect unique properties (i.e. tissue mechanics, density and type of immune cells) of the inflamed tissue or a specialized interaction between afferent and tissue. However, the fact that different modes of sensitization are observed in subpopulations of isolated sensory neurons in vitro, defined solely by target of innervation, suggests that unique attributes of afferents innervating the inflamed tissue contributes to the differential responses observed in different tissues [85]. Importantly, because these different response patterns appear to reflect the differential activation of specific classes of ion channels, these observations suggest that it may be possible to treat pain arising from specific body regions with specific pharmacological interventions.

\section{Hormones}

The question of whether there is a difference between men and women with respect to pain threshold and tolerance has been vigorously debated and tested in a multitude of experimental paradigms. The present consensus of all this work, well summarized in a number of excellent reviews, is that while the differences are subtle and not always manifest, when they are present, it is women who are more sensitive to noxious stimulation [89-91]. Where there is little debate, however, is over the question about whether there is a sex difference in the expression of persistent, particularly inflammatory, pain. Women are, in general, much more likely to suffer from inflammatory pain and when they do, the pain is generally more intense and longer lasting [92, 89, 93]. Consistent with this generality is the observation that women are more likely to suffer from chronic pain syndromes such as migraine, temporomandibular disorder (TMD) and fibromyalgia. 
An increase in funding from the National Institutes of Health in combination with the broad acceptance within the pain research community that there is a sex difference in pain processing has spurred a dramatic increase in research into the basis for this sex difference.

Because gonadal hormones are primarily responsible for many structural and functional differences between males and females, researchers have focused on the role of gonadal hormones in mediating the sex difference in nociception and the response to injury. The primary male gonadal hormone, testosterone, does appear to have a subtle influence on nociception and the inflammatory response, but these effects are, for the most part, relatively minor [94]. Progesterone and estrogen, the two primary gonadal hormones in females, appear to exert largely opposing influences on nociception. Progesterone, at least at high plasma concentrations, is largely antinociceptive [95-98]. It appears to exert this effect through CNS circuitry, although it also influences the peripheral nervous system. In contrast, estrogen appears to be largely pronociceptive. Its mechanisms of action are complex, as estrogen has been shown to influence structures relevant to nociception throughout the body. Timing, with respect to estrogen cycling or the sustained application of estrogen (as in the case of hormone replacement therapy), site of action and dependent measures of nociception all appear to be important factors when assessing the impact of estrogen on specific aspects of nociceptive processing. Much of this complexity in the influence of estrogen has been observed at the level of the primary afferent neuron, which appears to be critically involved in the pro-nociceptive actions of this hormone.

Primary afferent neurons express both of the known isoforms of the estrogen receptor (ER), ER $\alpha$ and $\mathrm{ER} \beta$, and thus they possess the substrate for a direct action of estrogen. Expression of ER $\alpha$ appears to be primarily restricted to a subpopulation of sensory neurons with a small cell body diameter [99, 100]. Given the rough correlation between cell body size and axon conduction velocity, this distribution suggests ER $\alpha$ may be primarily present in nociceptive afferents. ER $\beta$ appears to be more widely distributed, as it is present in both small and large diameter sensory neurons [99, 100]. While estrogen, like other hormones, was originally thought to influence cellular processes at the transcriptional level, it has more recently been appreciated that estrogen acutely influences cellular processes, through an action at cytoplasmic or even membrane-bound receptors [101, 102]. Both processes have been described in sensory neurons.
The clearest example of an acute effect of estrogen on sensory neurons is inhibition of voltage-gated calcium channels. This inhibition is selective for L-type calcium channels and appears to reflect activation of a plasma membrane ER [103]. In support of the suggestion that calcium channel inhibition occurs independently of nuclear effects, the inhibition is observed within $5 \mathrm{~min}$ of estrogen application and is readily reversible. Given that this inhibition was demonstrated on isolated sensory neuron cell bodies in vitro with calcium imaging, it is difficult to predict how this change would influence nociceptor excitability in vivo. That is, if the L-type channels were closely coupled to a calcium-dependent potassium channel, this estrogen-induced inhibition of calcium influx could result in a net increase in excitability secondary to a decrease in potassium channel activity. In contrast, if these L-type channels contributed to the calcium influx associated with transmitter release, then inhibition of these channels would be inhibitory.

An example of a genomic influence of estrogen on sensory neurons is the estrogen-induced increase in the expression of both NGF and the high-affinity NGF receptor TrkA [99, 104-106]. The observation that estrogen influences TrkA expression has profound implications for the neuronal response to inflammation, given the compelling evidence that NGF plays a critical role in the inflammatory response in general and the pain associated with inflammation in particular [107]. Estrogen has also been shown to increase the expression of CGRP [108]. This has further implications for pain and inflammation given the importance of CGRP in the development of neurogenic inflammation, as well as more recent data indicating that CGRP can act in an autocrine fashion to directly activate nociceptive afferents [109].

There is also evidence for both dynamic and tonic regulation of afferent excitability by estrogen and/or fluctuating hormone levels. One of the most elegant examples of dynamic regulation comes from a study of afferent innervation of the reproductive organs in female rats [110]. In this study, it was demonstrated that the excitability of afferents innervating the reproductive organs varied with estrus cycle such that the greatest sensitivity was observed at a time in the cycle that would be most favorable to reproduction. Consistent with the suggestion that there are differences among subpopulations of sensory neurons, the same group failed to detect evidence of changes in the sensitivity of bladder afferents associated with stages of the estrus cycle [111]. Interestingly, there were changes in bladder sensitivity associated with changes in the estrus cycle following inflammation of the bladder. 
While there is clearly evidence for estrus cycle-dependent changes in afferent excitability, the tonic regulation of afferent excitability in rodents appears to be a more common phenomenon. For example, glutamate-evoked activity in afferents innervating the temporomandibular joint (TMJ) is significantly greater in female rats compared to male rats, and there is at least preliminary data suggesting that excitability of TMJ afferents in female rats does not vary across the estrus cycle [112]. However, this sex difference does appear to be regulated by estrogen as it is eliminated by ovariectomy and reconstituted with estrogen replacement [113]. Second messenger pathways utilized by inflammatory mediators also appear to be under tonic regulation. For example, PKA-, PKC $\varepsilon$ - and NOdependent pathways appear to underlie epinephrine-induced hyperalgesia in male but not female rats [114]. A role for estrogen in the regulation of the female phenotype is implicated by the observation that ovariectomy induces a male phenotype and estrogen replacement restores the female phenotype. Interestingly, the inflammation-induced priming described earlier, whereby an initial inflammatory insult influences the duration and second messenger pathways underlying re-inflammation, appears to be under tonic inhibition by estrogen [115]. That is, this priming is observed in males and females following ovariectomy but not in intact females. And it is blocked by estrogen replacement in ovariectomized females.

The presence of an apparently tonic regulation of nociceptive sensitivity in the rat, compared to the relatively common, although not always consistent association between pain sensitivity and stage of menstrual cycle in humans, raises the possibility that the estrus cycle in the rodent is too short to effectively detect the impact of a changing hormonal milieu. That is, the molecules underlying hormone-induced changes in nociception in rodents may not cycle as rapidly as the hormone levels do. Such a possibility would suggest that it is not only important to assess nociception in rodents under conditions in which hormonal levels have been artificially manipulated, but to do so over a time frame longer than is required for the completion of a single estrus cycle.

\section{Conclusion}

The challenge that continues to lie before the pain research community is the adequate and appropriate treatment of persistent pain, for which there still are minimal therapeutic options. While it is clear from the preceding discussion that we have made significant advances in our understanding of one of the fundamental processes responsible for much of the persistent pain experienced today, these advances come with a mixed message. The bad news is that the more we learn, the greater the apparent barriers to a novel therapeutic intervention; there are too many new targets, too many parallel pathways, and the worst news of all, there are significant differences among subpopulations of afferents defined solely by tissue of innervation, suggesting that one intervention will not work for pain arising from all tissue types. On the other hand, the good news is that there are still a few targets out there such as TRPV1 and NaV1.8 that appear to be critical for the development and maintenance of sensitization as well as points of convergence for multiple second messenger pathways and multiple inflammatory mediators. Thus, targeting these molecules still offers the hope of effective pain relief with minimal side effects.

\section{Acknowledgements}

We would like to thank Drs. Joel Greenspan and Ronald Dubner for helpful comments during the preparation of the manuscript. Some of the studies discussed in this review were supported by NIH grants P50 AR049555 and P01 NS41384.

\section{References}

1 Bevan S: Nociceptive peripheral neurons: cellular properties; in Wall PD, Melzack R (eds): Textbook of Pain. Edinburgh, Churchill-Livingstone, 1999, vol pp 85-103.

2 Levine JD, Reichling DB: Peripheral mechanisms of inflammatory pain; in Wall PD, Melzack R (eds): Textbook of Pain. New York, Harcourt, 1999, vol pp 59-84.
3 Raja SN, Meyer RA, Ringkamp M, Campbell JN: Peripheral neural mechanisms of nociception; in Wall PD, Melzack R (eds): Textbook of Pain. Edinburgh, Churchill-Livingstone, 1999, vol pp 11-57.

4 Sluka KA, Willis WD, Westlund KN: The role of dorsal root reflexes in neurogenic inflammation. Pain Forum 1995;4:141-149.

5 Gold MS: Tetrodotoxin-resistant $\mathrm{Na}^{+}$currents and inflammatory hyperalgesia. Proc Natl Acad Sci USA 1999;96:7645-7649.
6 Djouhri L, Lawson SN: Increased conduction velocity of nociceptive primary afferent neurons during unilateral hindlimb inflammation in the anaesthetised guinea-pig. Neuroscience 2001;102:669-679.

7 Julius D, Basbaum AI: Molecular mechanisms of nociception. Nature 2001;413:203-210.

-8 Richardson JD, Vasko MR: Cellular mechanisms of neurogenic inflammation. J Pharmacol Exp Ther 2002;302:839-845. 
9 Gold MS: Membrane properties: ion channels; in Kruger L (ed): Methods in Pain Research. New York, CRC Press, 2001, vol pp 169186.

10 Brock JA, McLachlan EM, Belmonte C: Tetrodotoxin-resistant impulses in single nociceptor nerve terminals in guinea-pig cornea. J Physiol (Lond) 1998;512:211-217.

11 Carr RW, Pianova S, Brock JA: The effects of polarizing current on nerve terminal impulses recorded from polymodal and cold receptors in the guinea-pig cornea. J Gen Physiol 2002;120: 395-405.

12 Khasar SG, Gold MS, Levine JD: A tetrodotoxin-resistant sodium current mediates inflammatory pain in the rat. Neurosci Lett 1998 256:17-20.

-13 Porreca F, Lai J, Bian D, Wegert S, Ossipov MH, Eglen RM, Kassotakis L, Novakovic S, Rabert DK, Sangameswaran L, Hunter JC: A comparison of the potential role of the tetrodotoxin-insensitive sodium channels, PN3/SNS and NaN/SNS2, in rat models of chronic pain. Proc Natl Acad Sci USA 1999;96:7640-7644.

14 Fitzgerald EM, Okuse K, Wood JN, Dolphin AC, Moss SJ: cAmp-dependent phosphorylation of the tetrodotoxin-resistant voltage-dependent sodium channel Sns. J Physiol (Lond) 1999;516:433-446.

-15 Tanaka M, Cummins TR, Ishikawa K, DibHajj SD, Black JA, Waxman SG: SNS $\mathrm{Na}^{+}$ channel expression increases in dorsal root ganglion neurons in the carrageenan inflammatory pain model. Neuroreport 1998;9:967972

16 Takigawa T, Alzheimer C, Quasthoff S, Grafe P: A special blocker reveals the presence and function of the hyperpolarization-activated cation current $\mathrm{IH}$ in peripheral mammalian nerve fibres. Neuroscience 1998;82:631-634.

17 Borgland SL, Connor M, Ryan RM, Ball HJ, Christie MJ: Prostaglandin E(2) inhibits calcium current in two sub-populations of acutely isolated mouse trigeminal sensory neurons. J Physiol 2002;539:433-444.

- 18 Taiwo YO, Bjerknes LK, Goetzl EJ, Levine JD: Mediation of primary afferent peripheral hyperalgesia by the cAMP second messenger system. Neuroscience 1989;32:577-580.

19 Khasar SG, McCarter G, Levine JD: Epinephrine produces a beta-adrenergic receptor-mediated mechanical hyperalgesia and in vitro sensitization of rat nociceptors. J Neurophysiol 1999;81:1104-1112.

20 Schepelmann K, Messlinger K, Schmidt RF: The effects of phorbol ester on slowly conducting afferents of the cat's knee joint. Exp Brain Res 1993;92:391-398.

21 Kress M, Rodl J, Reeh PW: Stable analogues of cyclic AMP but not cyclic GMP sensitize unmyelinated primary afferents in rat skin to heat stimulation but not to inflammatory mediators, in vitro. Neuroscience 1996;74:609_ 617
22 Mizumura K, Koda H, Kumazawa T: Opposite effects of increases in intracellular cyclic AMP on the heat and bradykinin responses of canine visceral polymodal receptors in vitro. Neurosci Res 1996;25:335-341.

23 Wang JF, Khasar SG, Ahlgren SC, Levine JD: Sensitization of C-fibres by prostaglandin E2 in the rat is inhibited by guanosine $5^{\prime}-\mathrm{O}-(2-$ thiodiphosphate), 2',5'-dideoxyadenosine and Walsh inhibitor peptide. Neuroscience 1996; 71:259-263.

24 Mizumura K, Koda H, Kumazawa T: Possible contribution of protein kinase $\mathrm{C}$ in the effects of histamine on the visceral nociceptor activities in vitro. Neurosci Res 2000;37:183-190.

25 Levy D, Strassman AM: Distinct sensitizing effects of the cAMP-PKA second messenger cascade on rat dural mechanonociceptors. J Physiol 2002;538:483-493.

26 Cui M, Nicol GD: Cyclic AMP mediates the prostaglandin $\mathrm{E}_{2}$-induced potentiation of bradykinin excitation in rat sensory neurons. Neuroscience 1995;66:459-466.

27 England S, Bevan S, Docherty RJ: $\mathrm{PGE}_{2}$ modulates the tetrodotoxin-resistant sodium current in neonaatal rat dorsal root ganglion neurons via the cyclic AMP-protein kinase A cascade. J Physiol (Lond) 1996;495:429-440.

- 28 Nicol GD, Vasko MR, Evans AR: Prostaglandins suppress an outward potassium current in embryonic rat sensory neurons. J Neurophysiol 1997;77:167-176.

29 Gold MS, Levine JD, Correa AM: Modulation of TTX-R INa by PKC and PKA and their role in PGE2-induced sensitization of rat sensory neurons in vitro. J Neurosci 1998:18:1034510355.

30 Lopshire JC, Nicol GD: The cAMP transduction cascade mediates the prostaglandin E2 enhancement of the capsaicin-elicited current in rat sensory neurons: whole-cell and singlechannel studies. J Neurosci 1998;18:60816092 .

- 31 Cesare P, Dekker LV, Sardini A, Parker PJ, McNaughton PA: Specific involvement of PKC-epsilon in sensitization of the neuronal response to painful heat. Neuron 1999;23: 617-624.

32 Zhang YH, Kenyon JL, Nicol GD: Phorbol ester-induced inhibition of potassium currents in rat sensory neurons requires voltage-dependent entry of calcium. J Neurophysiol 2001;85 362-373.

- 33 Bhave G, Zhu W, Wang H, Brasier DJ, Oxford GS, Gereau RWt: cAMP-dependent protein kinase regulates desensitization of the capsaicin receptor (VR1) by direct phosphorylation. Neuron 2002;35:721-731.

34 Numazaki M, Tominaga T, Toyooka H, Tominaga M: Direct phosphorylation of capsaicin receptor VR1 by protein kinase $\mathrm{C}$ epsilon and identification of two target serine residues. $\mathrm{J}$ Biol Chem 2002;277:13375-13378.

- 35 Rathee PK, Distler C, Obreja O, Neuhuber W, Wang GK, Wang SY, Nau C, Kress M: PKA/ AKAP/VR-1 module: a common link of Gsmediated signaling to thermal hyperalgesia. J Neurosci 2002;22:4740-4745.
36 Khasar SG, Lin YH, Martin A, Dadgar J, McMahon T, Wang D, Hundle B, Aley KO, Isenberg W, McCarter G, Green PG, Hodge CW, Levine JD, Messing RO: A novel nociceptor signaling pathway revealed in protein kinase $\mathrm{C}$ epsilon mutant mice. Neuron 1999;24:253260.

37 Zhou Y, Li GD, Zhao ZQ: State-dependent phosphorylation of epsilon-isozyme of protein kinase $\mathrm{C}$ in adult rat dorsal root ganglia after inflammation and nerve injury. J Neurochem 2003;85:571-580.

38 Dina OA, McCarter GC, de Coupade C, Levine JD: Role of the sensory neuron cytoskeleton in second messenger signaling for inflammatory pain. Neuron 2003;39:613-624.

39 Olah Z, Karai L, Iadarola MJ: Protein kinase $\mathrm{C}($ alpha) is required for vanilloid receptor 1 activation: evidence for multiple signaling pathways. J Biol Chem 2002;277:3575235759.

40 Duarte ID, dos Santos IR, Lorenzetti BB, Ferreira SH: Analgesia by direct antagonism of nociceptor sensitization involves the argininenitric oxide-cGMP pathway. Eur J Pharmacol 1992;217:225-227.

41 Nakamura A, Fujita M, Shiomi H: Involvement of endogenous nitric oxide in the mechanism of bradykinin-induced peripheral hyperalgesia. Br J Pharmacol 1996;117:407-412.

42 Holthusen $\mathrm{H}$ : Involvement of the $\mathrm{NO} /$ cyclic GMP pathway in bradykinin-evoked pain from veins in humans. Pain 1997;69:87-92.

43 Aley KO, McCarter G, Levine JD: Nitric oxide signaling in pain and nociceptor sensitization in the rat. J Neurosci 1998:18:7008-7014.

- 44 Kelly DC, Asghar AU, Marr CG, McQueen DS: Nitric oxide modulates articular sensory discharge and responsiveness to bradykinin in normal and arthritic rats in vivo. Neuroreport 2001;12:121-125.

45 Chen X, Levine JD: NOS inhibitor antagonism of PGE2-induced mechanical sensitization of cutaneous $\mathrm{C}$-fiber nociceptors in the rat. J Neurophysiol 1999;81:963-966.

46 Sachs D, Cunha FQ, Ferreira SH: Peripheral analgesic blockade of hypernociception: activation of arginine/ $\mathrm{NO} / \mathrm{cGMP} /$ protein kinase G/ATP-sensitive $\mathrm{K}^{+}$channel pathway. Proc Natl Acad Sci USA 2004;101:3680-3685.

47 Vivancos GG, Parada CA, Ferreira SH: Opposite nociceptive effects of the arginine/NO/ cGMP pathway stimulation in dermal and subcutaneous tissues. Br J Pharmacol 2003;138: 1351-1357.

48 Levy D, Strassman AM: Modulation of dural nociceptor mechanosensitivity by the nitric oxide-cyclic GMP signaling cascade. J Neurophysiol 2004.

49 Prescott ED, Julius D: A modular PIP2 binding site as a determinant of capsaicin receptor sensitivity. Science 2003;300:1284-1288.

-50 Bonnington JK, McNaughton PA: Signalling pathways involved in the sensitisation of mouse nociceptive neurones by nerve growth factor. J Physiol 2003;551:433-446. 
-51 Zhang YH, Vasko MR, Nicol GD: Ceramide, a putative second messenger for nerve growth factor, modulates the TTX-resistant $\mathrm{Na}(+)$ current and delayed rectifier $\mathrm{K}(+)$ current in rat sensory neurons. J Physiol 2002;544:385402.

-52 Dobrowsky RT, Werner MH, Castellino AM, Chao MV, Hannun YA: Activation of the sphingomyelin cycle through the low-affinity neurotrophin receptor. Science 1994;265: 1596-1599.

-53 Bergmann I, Reiter R, Toyka KV, Koltzenburg $\mathrm{M}$ : Nerve growth factor evokes hyperalgesia in mice lacking the low-affinity neurotrophin receptor p75. Neurosci Lett 1998;255:87-90.

54 von Schack D, Casademunt E, Schweigreiter R, Meyer M, Bibel M, Dechant G: Complete ablation of the neurotrophin receptor p75NTR causes defects both in the nervous and the vascular system. Nat Neurosci 2001;4:977-978.

-55 Obata K, Yamanaka H, Dai Y, Tachibana T, Fukuoka T, Tokunaga A, Yoshikawa H, Noguchi K: Differential activation of extracellular signal-regulated protein kinase in primary afferent neurons regulates brain-derived neurotrophic factor expression after peripheral inflammation and nerve injury. J Neurosci 2003; 23:4117-4126.

-56 Kim SY, Bae JC, Kim JY, Lee HL, Lee KM, Kim DS, Cho HJ: Activation of p38 MAP kinase in the rat dorsal root ganglia and spinal cord following peripheral inflammation and nerve injury. Neuroreport 2002;13:24832486.

- 57 Jin SX, Zhuang ZY, Woolf CJ, Ji RR: p38 mitogen-activated protein kinase is activated after a spinal nerve ligation in spinal cord microglia and dorsal root ganglion neurons and contributes to the generation of neuropathic pain. J Neurosci 2003;23:4017-4022.

- 58 Ji RR, Samad TA, Jin SX, Schmoll R, Woolf CJ: p38 MAPK activation by NGF in primary sensory neurons after inflammation increases TRPV1 levels and maintains heat hyperalgesia. Neuron 2002;36:57-68.

-59 Aley KO, Martin A, McMahon T, Mok J, Levine JD, Messing RO: Nociceptor sensitization by extracellular signal-regulated kinases. $\mathrm{J}$ Neurosci 2001;21:6933-6939.

-60 Hu HJ, Glauner KS, Gereau RWt: ERK integrates PKA and PKC signaling in superficial dorsal horn neurons. I. Modulation of A-type $\mathrm{K}^{+}$currents. J Neurophysiol 2003;90:16711679.

61 Dai Y, Iwata K, Fukuoka T, Kondo E, Tokunaga A, Yamanaka $H$, Tachibana T, Liu Y, Noguchi K: Phosphorylation of extracellular signal-regulated kinase in primary afferent neurons by noxious stimuli and its involvement in peripheral sensitization. J Neurosci 2002;22:7737-7745.

-62 Dai Y, Fukuoka T, Wang H, Yamanaka H, Obata K, Tokunaga A, Noguchi K: Contribution of sensitized $\mathrm{P} 2 \mathrm{X}$ receptors in inflamed tissue to the mechanical hypersensitivity revealed by phosphorylated ERK in DRG neurons. Pain 2004;108:258-266.
63 Rosen LB, Ginty DD, Weber MJ, Greenberg ME: Membrane depolarization and calcium influx stimulate MEK and MAP kinase via activation of Ras. Neuron 1994;12:1207-1221.

64 Delcroix JD, Valletta JS, Wu C, Hunt SJ, Kowal AS, Mobley WC: NGF signaling in sensory neurons: evidence that early endosomes carry NGF retrograde signals. Neuron 2003;39:6984.

65 Carlton SM: Localization of CaMKII-alpha in rat primary sensory neurons: increase in inflammation. Brain Res 2002;947:252-259.

66 Kayser V, Idanpaan-Heikkila JJ, Guilbaud G: Sensitization of the nervous system, induced by two successive hindpaw inflammations, is suppressed by a local anesthetic. Brain Res 1998;794:19-27.

-67 Aley KO, Messing RO, Mochly-Rosen D, Levine JD: Chronic hypersensitivity for inflammatory nociceptor sensitization mediated by the epsilon isozyme of protein kinase $\mathrm{C}$. $\mathrm{J}$ Neurosci 2000;20:4680-4685.

68 Perrot S, Guilbaud G, Kayser V: Differential behavioral effects of peripheral and systemic morphine and naloxone in a rat model of repeated acute inflammation. Anesthesiology 2001;94:870-875.

69 Yokoyama K, Kurihara T, Makita K, Tanabe T: Plastic change of N-type Ca channel expression after preconditioning is responsible for prostaglandin $\mathrm{E}_{2}$-induced long-lasting allodynia. Anesthesiology 2003;99:1364-1370.

70 Parada CA, Yeh JJ, Reichling DB, Levine JD: Transient attenuation of protein kinase $\mathrm{C}$ epsilon can terminate a chronic hyperalgesic state in the rat. Neuroscience 2003;120:219-226.

71 Anand KJ, Coskun V, Thrivikraman KV, Nemeroff CB, Plotsky PM: Long-term behavioral effects of repetitive pain in neonatal rat pups. Physiol Behav 1999;66:627-637.

72 Ruda MA, Ling QD, Hohmann AG, Peng YB, Tachibana T: Altered nociceptive neuronal circuits after neonatal peripheral inflammation. Science 2000;289:628-631.

73 Lidow MS, Song ZM, Ren K: Long-term effects of short-lasting early local inflammatory insult. Neuroreport 2001;12:399-403.

74 Coutinho SV, Plotsky PM, Sablad M, Miller JC, Zhou H, Bayati AI, McRoberts JA, Mayer EA: Neonatal maternal separation alters stressinduced responses to viscerosomatic nociceptive stimuli in rat. Am J Physiol 2002;282: G307-G316.

-75 Lin C, Al-Chaer ED: Long-term sensitization of primary afferents in adult rats exposed to neonatal colon pain. Brain Res 2003;971:7382.

76 Ren K, Anseloni V, Zou S-P, Wade EB, Novikova SI, Ennis M, Traub RJ, Gold MS, Dubner R, Lidow MS: Characterization of basal and re-inflammation-associated long-term alteration in pain responsivity following shortlasting neonatal local inflammatory insult. Pain, in press.

77 Lidow MS: Long-term effects of neonatal pain on nociceptive systems. Pain 2002;99:377383.
78 Walker SM, Meredith-Middleton J, CookeYarborough C, Fitzgerald M: Neonatal inflammation and primary afferent terminal plasticity in the rat dorsal horn. Pain 2003;105: 185-195.

79 Yoshimura N, de Groat WC: Plasticity of $\mathrm{Na}^{+}$ channels in afferent neurones innervating rat urinary bladder following spinal cord injury. $\mathrm{J}$ Physiol (Lond) 1997;503:269-276.

80 Gold MS, Zhang L, Wrigley DL, Traub RJ: Prostaglandin E(2) modulates TTX-R I(Na) in rat colonic sensory neurons. J Neurophysiol 2002;88:1512-1522.

81 Moore BA, Stewart TM, Hill C, Vanner SJ: TNBS ileitis evokes hyperexcitability and changes in ionic membrane properties of nociceptive DRG neurons. Am J Physiol 2002;282: G1045-G1051.

82 Undem BJ, Oh EJ, Lancaster E, Weinreich D: Effect of extracellular calcium on excitability of guinea pig airway vagal afferent nerves. J Neurophysiol 2003;89:1196-1204.

83 Dang K, Bielefeldt K, Gebhart GF: Gastric ulcers reduce A-type potassium currents in rat gastric sensory ganglion neurons. Am J Physiol 2004;286:G573-G579.

84 Kang YM, Bielefeldt K, Gebhart GF: Sensitization of mechanosensitive gastric vagal afferent fibers in the rat by thermal and chemical stimuli and gastric ulcers. J Neurophysiol 2004;91:1981-1989.

85 Gold MS, Traub RJ: Cutaneous and colonic rat DRG neurons differ with respect to both baseline and $\mathrm{PGE}_{2}$-induced changes in passive and active electrophysiological properties. J Neurophysiol, in press.

86 Andrew D, Greenspan JD: Mechanical and heat sensitization of cutaneous nociceptors after peripheral inflammation in the rat. J Neurophysiol 1999;82:2649-2656.

87 Schaible HG, Schmidt RF: Excitation and sensitization of fine articular afferents from cat's knee joint by prostaglandin $E_{2}$. J Physiol 1988 ; 403:91-104.

88 Su X, Sengupta JN, Gebhart GF: Effects of opioids on mechanosensitive pelvic nerve afferent fibers innervating the urinary bladder of the bat. J Neurophysiol 1997;77:1566-1580.

89 Berkley KJ: Sex differences in pain. Behav Brain Sci 1997;20:371-380.

90 Fillingim RB: Sex, gender, and pain: women and men really are different. Curr Rev Pain 2000;4:24-30.

91 Craft RM: Sex differences in opioid analgesia: 'from mouse to man'. Clin J Pain 2003; 19: 175-186.

92 Unruh AM: Gender variations in clinical pain experience. Pain 1996;65:123-167.

93 LeResche L: Epidemiology of temporomandibular disorders: implications for the investigation of etiologic factors. Crit Rev Oral Biol Med 1997;8:291-305.

94 Green PG, Dahlqvist SR, Isenberg WM, Strausbaugh HJ, Miao FJ, Levine JD: Sex steroid regulation of the inflammatory response: sympathoadrenal dependence in the female rat. J Neurosci 1999;19:4082-4089. 
-95 Gintzler AR: Endorphin-mediated increases in pain threshold during pregnancy. Science 1980;210:193-195.

96 Cogan R, Spinnato JA: Pain and discomfort thresholds in late pregnancy. Pain 1986;27: 63-68.

-97 Gintzler AR, Bohan MC: Pain thresholds are elevated during pseudopregnancy. Brain Res 1990;507:312-316.

98 Frye CA, Walf AA, Rhodes ME, Harney JP: Progesterone enhances motor, anxiolytic, analgesic, and antidepressive behavior of wildtype mice, but not those deficient in type 1 5-alpha-reductase. Brain Res 2004;1004: 116-124.

\$9 Sohrabji F, Miranda RC, Toran-Allerand $\mathrm{CD}$ : Estrogen differentially regulates estrogen and nerve growth factor receptor mRNAs in adult sensory neurons. J Neurosci 1994;14: 459-471.

100 Taleghany N, Sarajari S, DonCarlos LL, Gollapudi L, Oblinger MM: Differential expression of estrogen receptor alpha and beta in rat dorsal root ganglion neurons. J Neurosci Res 1999;57:603-615.

101 Toran-Allerand CD, Singh M, Setalo G Jr: Novel mechanisms of estrogen action in the brain: new players in an old story. Front Neuroendocrinol 1999;20:97-121.
102 Toran-Allerand CD, Guan X, MacLusky NJ, Horvath TL, Diano S, Singh M, Connolly ES Jr, Nethrapalli IS, Tinnikov AA: ER-X: a novel, plasma membrane-associated, putative estrogen receptor that is regulated during development and after ischemic brain injury. J Neurosci 2002;22:8391-8401.

103 Chaban VV, Mayer EA, Ennes HS, Micevych PE: Estradiol inhibits atp-induced intracellular calcium concentration increase in dorsal root ganglia neurons. Neuroscience 2003; 118:941-948.

104 Liuzzi FJ, Scoville SA, Bufton SM: Longterm estrogen replacement coordinately decreases trkA and beta-PPT mRNA levels in dorsal root ganglion neurons. Exp Neurol 1999;155:260-267.

105 Lanlua P, Decorti F, Gangula PR, Chung K, Taglialatela G, Yallampalli C: Female steroid hormones modulate receptors for nerve growth factor in rat dorsal root ganglia. Biol Reprod 2001;64:331-338.

106 Bjorling DE, Beckman M, Clayton MK, Wang ZY: Modulation of nerve growth factor in peripheral organs by estrogen and progesterone. Neuroscience 2002;110:155-167.

107 Shu XQ, Mendell LM: Neurotrophins and hyperalgesia. Proc Natl Acad Sci USA 1999; 96:7693-7696.

108 Gangula PR, Wimalawansa SJ, Yallampalli C: Pregnancy and sex steroid hormones enhance circulating calcitonin gene-related peptide concentrations in rats. Hum Reprod 2000;15:949-953.
09 Segond von Banchet G, Pastor A, Biskup C, Schlegel C, Benndorf K, Schaible HG: Localization of functional calcitonin gene-related peptide binding sites in a subpopulation of cultured dorsal root ganglion neurons. Neuroscience 2002;110:131-145.

110 Berkley KJ, Robbins A, Sato Y: Functional differences between afferent fibers in the hypogastric and pelvic nerves innervating female reproductive organs in the rat. J Neurophysiol 1993;69:533-544.

111 Johnson OL, Berkley KJ: Estrous influences on micturition thresholds of the female rat before and after bladder inflammation. Am J Physiol 2002;282:R289-R294.

112 Cairns BE, Sessle BJ, Hu JW: Characteristics of glutamate-evoked temporomandibular joint afferent activity in the rat. J Neurophysiol 2001;85:2446-2454.

113 Cairns BE, Sim Y, Bereiter DA, Sessle BJ, Hu JW: Influence of sex on reflex jaw muscle activity evoked from the rat temporomandibular joint. Brain Res 2002;957:338-344.

114 Dina OA, Aley KO, Isenberg W, Messing RO, Levine JD: Sex hormones regulate the contribution of PKC epsilon and PKA signalling in inflammatory pain in the rat. Eur J Neurosci 2001;13:2227-2233.

115 Joseph EK, Parada CA, Levine JD: Hyperalgesic priming in the rat demonstrates marked sexual dimorphism. Pain 2003;105:143150. 